\title{
The demand for sports and exercise: results from an illustrative survey
}

\author{
Nana Kwame Anokye • Subhash Pokhrel • \\ Martin Buxton · Julia Fox-Rushby
}

Received: 7 September 2010/Accepted: 7 February 2011/Published online: 23 February 2011

(C) The Author(s) 2011. This article is published with open access at Springerlink.com

\begin{abstract}
There is a paucity of empirical evidence on the extent to which price and perceived benefits affect the level of participation in sports and exercise. Using an illustrative sample of 60 adults at Brunel University, West London, we investigate the determinants of demand for sports and exercise. The data were collected through face-to-face interviews that covered indicators of sports and exercise behaviour; money/time price and perceived benefits of participation; and socio-economic/demographic details. Count, linear and probit regression models were fitted as appropriate. Seventy eight per cent of the sample participated in sports and exercise and spent an average of $£ 27$ per month and an average of 20 min travelling per occasion of sports and exercise. The demand for sport and exercise was negatively associated with time (travel or access time) and 'variable' price and positively correlated with 'fixed' price. Demand was price inelastic, except in the case of meeting the UK government's recommended level of participation, which is time price elastic (elasticity $=-2.2$ ). The implications of data from a larger nationally representative sample as well as the role of economic incentives in influencing uptake of sports and exercise are discussed.
\end{abstract}

Keywords Demand - Sports and exercise - Price . Time price $\cdot$ Public health

JEL Classification I18

N. K. Anokye $(\bowtie) \cdot S$. Pokhrel · M. Buxton · J. Fox-Rushby Health Economics Research Group (HERG), Brunel University, Uxbridge, Middlesex UB8 3PH, UK

e-mail: Nana.Anokye@brunel.ac.uk

\section{Introduction}

Physical inactivity is a major public health concern in England as it is associated with about 20 health conditions including coronary heart disease, cancer, diabetes and stroke [1-4] and is rated among the top ten leading causes of death in high-income countries [5, 6]. It may also lead to reduced psychological well-being and social interaction [3] as well as increased absenteeism within the working population [2]. Physical activity is multifaceted and includes a wide range of activities such as sports and exercise, housework as well as occupational activity [6]. Only $40 \%$ of men and $28 \%$ of women in England are physically active i.e. they participate in physical activity of either moderate intensity for a minimum of $30 \mathrm{~min}$ on 5 days each week or vigorous intensity for a minimum of 20 min on 3 days each week [7]. This study focuses on the sports and exercise component of physical activity, as it represents a planned aspect often aimed at attaining health benefits [8] and, as such, can be relatively easily targeted by policies to increase activity. Also, it is subject to less measurement error since sports and exercise activities are usually premeditated and hence easier to recall by respondents [9].

Policy aims at increasing activity not only among the inactive but also among those who are active but do not participate sufficiently often or with sufficient intensity. Understanding of the determinants of sports and exercise participation could help to identify target areas for policy and the achievement of such objectives. The challenge that public health practitioners face in securing adherence to sports and exercise might be attributed partially to inadequate understanding of the economic factors influencing the degree to which an individual participates and is willing to change their behaviour [10-12]. Economic 
factors can play a key role in developing understanding of preferences of individuals, as the trade-off between scarce resources (time and money) by individuals is examined $[13,14]$, and any efforts to improve lifestyle behaviour must incorporate individual interests in order to be effective [15].

The available theoretical and empirical literature on the economics of participation in sports and exercise suggest the need to account for price (i.e. time and money price) and perceived benefits among other factors in explaining such behaviour $[11,12,16]$. To date, there is a paucity of studies looking at this issue, mainly due to the lack of relevant data [17]. A few studies [11, 12, 16] have explored the effects of price but only partially, with attempts limited to either assessing the impact of time price alone, using proxies to capture the opportunity cost of time $[11,12]$, or money price via the reduction in admission charges to exercise referral programs [18]. To the best of our knowledge, no study has collected and analysed data on both price and perceived benefits of sports and exercise participation. This study originated as the outcome of our search for data on both price and perceived benefits in relation to physical activity [19]. As no such data could be located, the best starting point was to collect similar data through a small scale survey [20].

The aim of this study is to investigate how the demand for sports and exercise is influenced by price and perceived benefits. The objectives are twofold: (a) to estimate how much it cost people to participate in sports and exercise, and describe what the sources of price are and; (b) to assess the impact of price and perceived benefits on sports and exercise, given participation. The paper intends to inform policies aimed at encouraging people to be more active as well as a future research agenda.

\section{Methods}

\section{Theoretical framework}

We use utility maximisation theory to explain why some individuals do more sports and exercise than others. We hypothesise that the utility in this case is derived from their consumption of sports and exercise and other goods, subject to budget and time constraints. Utility is maximised when the marginal rate of substitution (i.e. the rate at which individuals are willing to trade-off other goods for sports and exercise) equals the ratio of prices related to sports and exercise and other goods. This is also equal to the ratio of marginal utilities that individuals' derive from the consumption of sports and exercise and other goods. It suggests that a change in price (ceteris paribus) could change the quantity demanded of sports and exercise [11, 21]. When the price of sports and exercise falls (ceteris paribus), the equi-marginal principle is unbalanced as the individual obtains greater utility from an extra unit of sports and exercise than from other goods. To maintain the original level of utility, the individual will consume more of sports and exercise.

Treating sports and exercise as a commodity in this framework requires some further thought. People may want to consume sports and exercise in anticipation of not only health but nonhealth benefits as well [4]. Thus, depending on the type and degree of benefits anticipated, people are likely to consume more or less at a given price. These perceived benefits act as demand shifters and enter the demand function through the 'tastes' component. The challenge, however, is that, while the price components are well documented (e.g. entrance fees, travel time, etc.) in the economic literature, it is less clear what constitutes perceived benefits. To date, while economic research recognises the importance of these benefits in understanding physical activity behaviour, it has not explicitly accounted for them [19]. Therefore, operationalisation of this theoretical framework also requires knowledge from psychological models.

A review of psychological models such as theories of reasoned action, planned behaviour, transtheoretical model and social cognitive theory showed that the decision to adopt a new behaviour involves a thought process which considers the perceived benefits of the intended behaviour [19]. These perceived benefits cover both 'health' (e.g. 'to maintain good health') and 'non health' benefits (e.g. 'to have fun'). Thus for completeness, future specification of perceived benefits ought to reflect not only 'health' benefits but 'non health' as well.

To provide robust estimates for price and perceived benefits, a range of control variables were used [22]. These included socio-demographic and economic variables that in previous research had been shown to correlate with sports and exercise: gender, age, income, educational qualification, employment status, working hours and household characteristics such as number of children and adults in the household [11, 16, 23-28]. In addition, 'relative importance placed on perceived benefits' was included as control variable because it could moderate the relationship between perceived benefits and sports and exercise [29]. Based on previous research, we hypothesise that gender (male), income (high) and educational qualification (high) would be positively correlated with sports and exercise. Age and working hours were expected to have a negative 
influence while the expected effect of employment status (employed), number of children and adults in the household are not self-evident as past research has yielded mixed findings.

Data

Data were collected from face-to-face interviews conducted in November-December 2008 using an illustrative sample of 60 staff and students of Brunel University, West London. This convenience sample was considered because of resource constraints. Respondents were recruited via emails asking them to participate in this survey, sent on the authors' behalf to both staff and students, by managers of the schools in the university.

The interview schedule covered indicators of sports and exercise behaviour, money and time price (travel time), perceived benefits of participation and socio-economic and demographic details. Indicators of sports and exercise behaviour captured the level of participation in various activities (e.g. swimming, cycling, workout at gym/exercise bike/weight training, aerobics/keep fit/gymnastics/ dance for fitness, any other type of dancing, running/jogging, football/rugby, badminton/tennis, squash, and press/ sits ups) during the 4 weeks prior to survey date. Money price covered 'fixed' price (e.g. membership fees; joining fees; purchase of apparel, equipment, nutritional supplements; maintenance cost of equipment; insurance premiums; cost of medical care, excluding those covered by insurance or health providers) and 'variable' price (e.g. entrance, class, competition charges; cost of refreshment, equipment hire, childcare and transport ticket). Time price was captured as travel time (in minutes) to do sports and exercise, as time of doing the activity itself was considered as a dependent variable. Data on price per unit of activity and total price of participation during the past 4 weeks were captured.

Perceived benefits of sports and exercise were measured using two scores from 13 benefits (see Box 1) rated 1-5 ( $1=$ not at all; $2 ; 3 ; 4 ; 5=$ great deal) with 6 as 'don't know'. The first score reflects how much a person thinks sports and exercise could help him/her achieve the 13 items. The second reflects the respondent's view of the importance of the benefit from the 13 items to themselves.

To ensure valid and reliable data, questions that had been developed and previously administered in United Kingdom were used in the interviews where possible; questions on sports and exercise were taken from the Health Survey for England (2006) and perceived benefits taken from the Health Education Authority Survey of Activity \& Health (1991). Questions on money and time price were developed and pretested using standard techniques including expert evaluation, cognitive interviews and respondent debriefing to assess their validity and reliability [19].

Methods of analysis

Descriptive analysis

Means (standard deviation - SD) and median (inter quartile ranges-IQR) were calculated for continuous data, and only the latter for categorical data. For this purpose, the perceived benefits were treated as ordinal variables with 'don't know' responses (i.e. score ' 6 ') excluded.

\section{Bivariate analysis}

The relationship between sports and exercise behaviour and other variables (price, perceived benefits and control variables) were analysed using both parametric and nonparametric tests of association (Kendall rank correlation test, t-test, Mann-Whitney U test, Pearson correlation test, chi-squared test and Fischer exact test) depending on the nature of the variables. Only variables significant in these analyses ( $p$ value $\leq 10 \%$ ) were included as independent variables for the regression analyses.

\section{Regression models}

Count $(n=2)$, linear and probit regression models were fitted, respectively, for four dependent variables: number of days on which exercise was undertaken (any intensity or duration), number of days during which vigorously intensive exercise was undertaken for at least $20 \mathrm{~min}$, total time spent in exercising and whether or not the recommended level of participation was met (i.e. sports and exercise of vigorous intensity for a minimum of $20 \mathrm{~min}$ on 3 days). The negbin variant of count models was used as the estimated alpha parameters were greater than zero $(0.185$; $0.075)$ and highly significant $(p<0.001 ; p=0.003)$, and both dependent variables had a low number of zero observations. The regression analyses were limited to those who participated in sports and exercise, as the focus of this paper was to investigate the level of participation among those who are currently active. The observed data for the models may not have been random since it is conditioned on the participation in sports and exercise. Sample selection bias was therefore likely but could not be accounted for given the small number of observations.

Given the small sample size, individual unit price variables were collapsed into three variables, in line with the literature [11, 12, 17, 30]: 'fixed' money price, 'variable' money price and travel time. The perceived benefits and 'relative importance placed on perceived benefits' were each collapsed into a binary variable that took the value of 
one if the observed score lay between 3 and 5 but zero otherwise. To ensure sufficient comparable observations in the categories, income, which was originally specified as an ordinal variable, was analysed as a binary variable that took the value of one if the observed amount lies between $£ 830$ and $£ 2,899$ per month but zero if below $£ 830$. The other control variables maintained their original specifications in the analysis.

All models were subject to standard diagnostic tests. Marginal effects and elasticities, estimated at sample mean values of independent variables, were computed for each variable. The threshold for statistical significance was set at $\leq 10 \%$ in all analyses because of the exploratory nature of the study. All analyses were undertaken using Stata version 10.

Demand curves showing the relationship between time price, money 'variable' price (unit price) and the quantity demanded of sports and exercise correspondingly, were constructed based on predicted quantities demanded at different prices, ceteris paribus. We further demonstrated the shifts in demand as a result of changes in perceived benefits. To allow this, we hold the price constant at its mean and then use regression estimates to predict the number of days doing sports and exercise for when perceived benefits are high and low. Averages were then calculated for the predicted events and plotted.

\section{Results}

Description of sample

Sixty-three individuals expressed interest in participating in the survey but 60 people were interviewed due to time constraints. One hundred per cent completed the survey and there was no missing data. About $12 \%(n=13)$ of the respondents did not participate in any sports and exercise. Nonparticipants tended to be older (mean age: 29.8 years), women $(61.5 \%)$ or employed $(53.9 \%)$ but likely to undertake paid work for fewer hours (average of $19.7 \mathrm{~h}$ per week). These differences were not statistically significant, except for gender. The remaining results are presented only for those who participated in sports and exercise.

Table 1 shows that the sample was highly educated; $75 \%(n=35)$ had degree level qualifications and $25 \%$ held either ' $\mathrm{A}$ ' or ' $\mathrm{O}$ ' level qualifications. Of the sample, $66 \%$ $(n=31)$ were men. The mean age of the sample was 26.5 years $(\mathrm{SD}=6.0)$, and about half were employed. The majority $(60 \% ; n=28)$ had a personal net monthly income of below $£ 830$, with half of those observations falling between $£ 400$ and $£ 829$. Of those having a personal net monthly income greater than $£ 830(40 \% ; n=19)$, the
Box 1 List of benefits

The question for perceived benefits was: ....'tell me how much you would say sports and exercise could help you in the following things:

1. To relax and forget about your cares

2. To get together and meet other people

3. To have fun

4. To get out of doors

5. To feel a sense of achievement

6. To feel independent

7. To feel mentally alert

8. To feel in good shape physically

9. To learn new things

10. To look good

11. To control or lose weight

12. To seek adventure and excitement

13. To improve or maintain your health

Health education authority national survey of activity and health (HEANSAH) 1991

majority $(n=68 \% ; n=13)$ had between $£ 830$ and $£ 1,649$ and the remainder $£ 1,650-£ 2,899$.

Descriptive statistics of dependent variables

Table 2 shows that $34 \%(n=16)$ met the recommended level of sports and exercise participation for vigorous activity. On average, people exercised on 11 days during the past 4 weeks but exercised vigorously at the recommended duration on 9.3 days during that same period. An average of $692.6 \mathrm{~min}(11.5 \mathrm{~h})$ was spent doing any sports and exercise during the last 4 weeks prior to the survey date (Table 2). Half of the respondents, who exercised, spent at least $8 \mathrm{~h}$ during those 4 weeks doing sports and exercise with one spending $56 \mathrm{~h}$ while five spent an hour. Half of those, who exercised, did so on 10 days but vigorously (at the recommended duration) on 8 days.

\section{Observed price}

Table 3 summarises money price related to sports and exercise participation in the last 4 weeks. Individuals spent $£ 27.41$ on sports and exercise participation. The maximum amount spent was $£ 84.40(n=1)$ and the minimum zero $(n=6)$. Of the average total amount spent, $£ 21$ was spent on 'fixed' price. Membership fees contributed most to total spending (£9) and hiring sports equipment the least (£0.03). Consideration of median values did not change findings. People spent an average of 19.8 min travelling back and forth per occasion, with half spending $14 \mathrm{~min}$ and one person spending one and half hours. 
Table 1 Descriptive statistics of respondents

a All unemployed were students but not all students were unemployed

\begin{tabular}{|c|c|c|c|c|c|}
\hline Variables & Obs. & Mean(SD)/percentage & Median (IQR) & Min & $\operatorname{Max}$ \\
\hline Age & 47 & $26.5(6.0)$ & $24(22,29)$ & 18 & 44 \\
\hline Size of household & 47 & $3.8(2.9)$ & $3(2,5)$ & 1 & 15 \\
\hline No. of children in household & 47 & $0.4(0.7)$ & $0(0,1)$ & 0 & 2 \\
\hline No. of adults in household & 47 & $3.4(2.9)$ & $2(2,4)$ & 1 & 15 \\
\hline \multicolumn{6}{|l|}{ Personal income } \\
\hline$<£ 830$ & 28 & 59.6 & & & \\
\hline$£ 830-£ 2,899$ & 19 & 40.4 & & & \\
\hline \multicolumn{6}{|l|}{ Gender } \\
\hline Male & 31 & 66 & & & \\
\hline Female & 16 & 34 & & & \\
\hline \multicolumn{6}{|l|}{ Employment status } \\
\hline Employed & 23 & 51 & & & \\
\hline Not employed ${ }^{\mathrm{a}}$ & 24 & 49 & & & \\
\hline Working hours & 23 & $24.7(13.3)$ & $22.5(15,38)$ & 6 & 45 \\
\hline \multicolumn{6}{|l|}{ Educational qualification } \\
\hline Degree level & 35 & 75 & & & \\
\hline Below degree level & 12 & 25 & & & \\
\hline
\end{tabular}

Table 2 Descriptive statistics of dependent variables

\begin{tabular}{|c|c|c|c|c|c|}
\hline Variables & Obs. & Mean(SD)/percentage & Median(IQR) & Min & Max \\
\hline $\begin{array}{l}\text { No. of days on which sports and exercise } \\
\text { were undertaken in the last } 4 \text { weeks }\end{array}$ & 47 & $11.0(7.4)$ & $10(4,16)$ & 1 & 28 \\
\hline $\begin{array}{l}\text { Total time (mins) spent on sports } \\
\text { and exercise in the last } 4 \text { weeks }\end{array}$ & 47 & $692.6(720.6)$ & $480(180,970)$ & 60 & 3,360 \\
\hline \multicolumn{6}{|l|}{$\begin{array}{l}\text { Meet recommended level of sports } \\
\text { and exercise in the last } 4 \text { weeks }\end{array}$} \\
\hline Yes & 16 & 34 & & & \\
\hline No & 31 & 66 & & & \\
\hline $\begin{array}{l}\text { No. of days on which vigorously intensive sports } \\
\text { and exercise at recommended duration } \\
\text { was undertaken in the last } 4 \text { weeks }\end{array}$ & 47 & $9.3(7.5)$ & $8(2,16)$ & 0 & 28 \\
\hline
\end{tabular}

\section{Perceived benefits}

The median score for the entire list of 13 items of perceived benefits was 3 or more, indicating that the respondents would perceive all these benefits arising from sports and exercise participation. Each item had about $82 \%$ $(n=38)$ of scores between 3 and 5. 'To stay in good shape physically' and 'to improve or maintain your health' were the most commonly perceived benefits (median (IQR): 5(4, 5); score 3-5: 95\%), and 'to feel independent' the least (median (IQR): 3(1.5, 4); score 3-5: 65\%). All 13 items listed as possible perceived benefits had a median score of 3 or more (score 3-5: 88\%) for importance to them.

\section{Regression models}

Table 4 shows the estimates for each of the reduced regression models that were consistent with the base model in terms of a priori expectations about the signs of coefficients. Results first consider the influence of independent variables across models and then within models.

\section{Effects of price}

The demand for sports and exercise was negatively associated with time (travel or access time) and 'variable' price, but positively correlated with 'fixed' price. These results were consistent across models, though only travel time appeared statistically significant throughout. The number of days on which sports and exercise were undertaken was influenced by 'variable' and time price, with the former being the most influential ( $\mathrm{ME}=-1.14)$. Other indicators of sports and exercise are explained by 'fixed' and time price, with the latter having greater impact.

Demand was broadly price inelastic except for meeting the recommended level, which was time price elastic. At 
Table 3 Descriptive statistics of price $(n=47)(2008 £$ sterling)

\begin{tabular}{|c|c|c|c|c|}
\hline Price & Mean (SD) & Median (IQR) & $\operatorname{Min}(\mathrm{n})$ & $\operatorname{Max}(\mathrm{n})$ \\
\hline Total price & $27.4(25.5)$ & $19.5(9.2,47)$ & $0(6)$ & $84(1)$ \\
\hline Total 'fixed' price & $21.0(25.4)$ & $10(0,42)$ & $0(19)$ & $80(1)$ \\
\hline Total 'variable' price & $6.4(10.1)$ & $2.0(0,10.5)$ & $0(19)$ & $45(1)$ \\
\hline \multicolumn{5}{|l|}{ Components of 'fixed' price } \\
\hline Membership fees & 9 (14.6) & $0(0,17)$ & $0(30)$ & $50(2)$ \\
\hline Joining fees & $1.0(6.7)$ & $0(0,0)$ & $0(46)$ & $46(1)$ \\
\hline Price of apparel & $4.2(11.3)$ & $0(0,0)$ & $0(39)$ & $57(1)$ \\
\hline Price of equipment & $2.9(11.4)$ & $0(0,0)$ & $0(42)$ & $60(1)$ \\
\hline Maintenance price of equipment & $0.2(1.5)$ & $0(0,0)$ & $0(46)$ & $10(1)$ \\
\hline Price of nutritional supplements & $2.1(7.5)$ & $0(0,0)$ & $0(43)$ & $31(1)$ \\
\hline Price of medical care & $0.3(2.2)$ & $0(0,0)$ & $0(46)$ & $15(1)$ \\
\hline Price of insurance & $0.1(1.0)$ & $0(0,0)$ & $0(46)$ & $7(1)$ \\
\hline Other & $1.1(6.0)$ & $0(0,0)$ & $0(44)$ & $40(1)$ \\
\hline \multicolumn{5}{|l|}{ Components of 'variable' price } \\
\hline \multicolumn{5}{|l|}{ Entrance charges } \\
\hline Unit price & $1.3(1.8)$ & $0(0,2.8)$ & $0(27)$ & $8(1)$ \\
\hline Total price & $4.4(8.6)$ & $0(0,6)$ & $0(27)$ & $45(1)$ \\
\hline \multicolumn{5}{|l|}{ Competition charges } \\
\hline Unit price & $0.04(0.3)$ & $0(0,0)$ & $0(46)$ & $2(1)$ \\
\hline Total price & $0.2(1.2)$ & $0(0,0)$ & $0(46)$ & $8(1)$ \\
\hline \multicolumn{5}{|l|}{ Classes charges } \\
\hline Unit price & $0.06(0.4)$ & $0(0,0)$ & $0(46)$ & $3(1)$ \\
\hline Total price & $0.06(0.4)$ & $0(0,0)$ & $0(46)$ & $3(1)$ \\
\hline \multicolumn{5}{|l|}{ Price of refreshment } \\
\hline Unit price & $0.4(0.7)$ & $0(0,0.7)$ & $0(31)$ & $3(1)$ \\
\hline Total price & $1.6(3.5)$ & $0(0,1.5)$ & $0(31)$ & $16(1)$ \\
\hline \multicolumn{5}{|l|}{ Price of equipment hire } \\
\hline Unit price & $0.01(0.1)$ & $0(0,0)$ & $0(46)$ & $0.5(1)$ \\
\hline Total price & $0.03(0.2)$ & $0(0,0)$ & $0(46)$ & $1.5(1)$ \\
\hline \multicolumn{5}{|l|}{ Price of transport ticket } \\
\hline Unit price & $0.1(0.4)$ & $0(0,0)$ & $0(45)$ & $2(1)$ \\
\hline Total price & $0.1(0.6)$ & $0(0,0)$ & $0(45)$ & $4(1)$ \\
\hline Travel time (mins) & $19.8(17.8)$ & $14(7.5,30)$ & $2.5(2)$ & $90(1)$ \\
\hline
\end{tabular}

the mean time price (time price) of $19.8 \mathrm{~min}$, a $10 \%$ higher time price is associated with $4.7 \%$ fewer days and less time (6.4\%) doing sports and exercise (all things being equal) (see Table 4). The same high time price is correlated with a $20 \%$ lower likelihood of meeting the recommended level and $3.6 \%$ fewer days for vigorously intensive sports and exercise. For money price ('variable' price), a 10\% higher price is related to a $2.4 \%$ fewer days for sports and exercise. Figure $1 \mathrm{a}, \mathrm{b}$ show the demand curves that demonstrate a negative relationship between price and sports and exercise ceteris paribus, with the steepness of these curves reflecting price inelastic demand. For example, a $10 \%$ higher (from $£ 1.90$ to $£ 2.10$ ) money price is associated with $2.5 \%$ fewer days (from 9 to 8.8 ) for sports and exercise.
A $10 \%$ higher 'fixed' price was associated with $3 \%$ more time spent doing sports and exercise, and a $10.1 \%$ higher likelihood of meeting the recommended level of participation (Table 4). Individuals also did $2 \%$ more days of vigorously intensive sports and exercise if they had a $10 \%$ higher 'fixed' price.

\section{Effects of perceived benefits}

Only 'to relax, forget about your cares' and 'to look good' were significantly correlated with sports and exercise (Table 4). Individuals who felt that sports and exercise could help them 'relax and forget about their cares' did 3 more days of sports and exercise than those who had lower awareness. People who felt that sports and exercise could 
Table 4 Estimation results of regression models (reduced) of dependent variables

\begin{tabular}{|c|c|c|c|c|c|c|c|c|}
\hline \multirow[t]{3}{*}{ Independent variables } & \multicolumn{8}{|c|}{ Dependent variables } \\
\hline & \multicolumn{2}{|c|}{ Number of days } & \multicolumn{2}{|l|}{ Total time } & \multicolumn{2}{|c|}{ Meet recommended level } & \multicolumn{2}{|c|}{$\begin{array}{l}\text { No. of days } \\
\text { (vigorous activity) }\end{array}$} \\
\hline & Coef. $^{\mathrm{a}}$ & ME (Elas'ty) ${ }^{\mathrm{b}}$ & Coef. $^{\mathrm{a}}$ & ME (Elas'ty) ${ }^{\mathrm{b}}$ & Coef. $^{\mathrm{a}}$ & ME (Elas'ty) ${ }^{\mathrm{b}}$ & Coef. $^{\mathrm{a}}$ & ME (Elas'ty) ${ }^{\mathrm{b}}$ \\
\hline \multicolumn{9}{|l|}{ Unit price } \\
\hline 'Fixed' price & 0.00 & $0.04(0.09)$ & $0.01 * *$ & $0.01(0.30)$ & $0.03 * *$ & $0.01(1.05)$ & $0.01 * *$ & $0.07(0.20)$ \\
\hline 'Variable' price & $-0.13 * * *$ & $-1.14(-0.24)$ & -0.05 & $-0.05(-0.09)$ & -0.02 & $-0.00(-0.04)$ & -0.00 & $-0.03(-0.01)$ \\
\hline Time price (travel time) & $-0.02 * * *$ & $-0.21(-0.47)$ & $-0.03 * * *$ & $-0.03(-0.64)$ & $-0.07 * *$ & $-0.02(-2.15)$ & $-0.02 * *$ & $-0.13(-0.36)$ \\
\hline \multicolumn{9}{|l|}{ Perceived benefits } \\
\hline To relax, forget about your cares & $0.44 * *$ & 3.41 & 0.40 & 0.40 & 0.83 & 0.18 & 0.15 & 1.02 \\
\hline To feel a sense of achievement & -0.48 & -5.29 & -0.19 & -0.19 & & & -0.71 & -7.05 \\
\hline To learn new things & -0.11 & -0.98 & 0.13 & 0.13 & & & & \\
\hline To control or lose weight & & & & & -0.64 & -0.90 & 0.35 & 2.27 \\
\hline To look good & & & & & & & $1.40 * *$ & 6.71 \\
\hline \multicolumn{9}{|l|}{ Control variables } \\
\hline Personal income (high) & $0.30 *$ & 2.76 & 0.19 & 0.19 & 0.77 & 0.19 & 0.03 & 0.20 \\
\hline Age & $-0.06 * * *$ & $-0.54(-1.60)$ & & & & & & \\
\hline Gender (male) & & & $0.69 * *$ & 0.69 & & & $0.65 * *$ & 4.33 \\
\hline No. of observations & 47 & & 47 & & 47 & & 47 & \\
\hline Constant & 3.75 & & 5.71 & & -2.02 & & 1.55 & \\
\hline Linktest & $p=0.20$ & & $p=0.95$ & & $p=0.36$ & & $p=0.39$ & \\
\hline Goodness of fit & & & & & $p=0.66^{\mathrm{d}}$ & & & \\
\hline Test for heteroskedasticity & & & $p=0.44^{\mathrm{c}}$ & & & & & \\
\hline Normality test & & & $p=0.43$ & & & & & \\
\hline Adjusted $R$ squared & & & 0.38 & & & & & \\
\hline Pseudo $R$ squared & 0.18 & & & & 0.41 & & 0.14 & \\
\hline Akaike inform. criterion (AIC) & 284.63 & & 154.50 & & 69.80 & & 321.11 & \\
\hline Bayesian inform. criterion (BIC) & 310.53 & & 132.30 & & 53.15 & & 293.36 & \\
\hline
\end{tabular}

${ }^{a}$ Significance level of $1 \%(* * *), 5 \%(* *), 10 \%(*)$

${ }^{\mathrm{b}}$ Marginal effects (Elasticity calculated for only continuous variables)

${ }^{c}$ Chi-square $(1)=0.58$

${ }^{\mathrm{d}}$ Chi-square $(8)=5.90$. Average variance inflation factors (VIF) for the independent variables were 1.5 , and average tolerance levels were 0.7

help them 'to look good' did more than 6 extra days of vigorously intensive sports and exercise compared with those with lower awareness.

\section{Control variables}

Income was positively correlated with all indicators of sports and exercise though the association was significant only in the context of days on which sports and exercise were undertaken. Higher income earners (between $£ 830$ and £2,899) did 2 more days of sports and exercise compared with lower income earners (£830). Age was significantly associated with number of days on which sports and exercise were undertaken, albeit with smaller impact $(\mathrm{ME}=-0.54)$. Gender, however, had a significant relationship with two indicators of sports and exercise; men spent more time $(\mathrm{ME}=0.69)$ on sports and exercise than women and also on average did 4 more of days vigorously intensive sports and exercise.

\section{Shifts in demand curve}

Figure 2 demonstrates the shifts in demand for sports and exercise due to changes in perceived benefits ceteris paribus. At the mean money price, a higher awareness that sports and exercise could help 'relax and forget about cares' is associated with an outward shift in the demand curve (original demand curve is represented by middle curve) leading to more days (from 9 to 9.8) for sports and exercise. Conversely, at the same price, lower awareness about this benefit is associated with fewer days (from 9 to 6.1) for sports and exercise. A similar trend emerges when price is specified as travel time. 

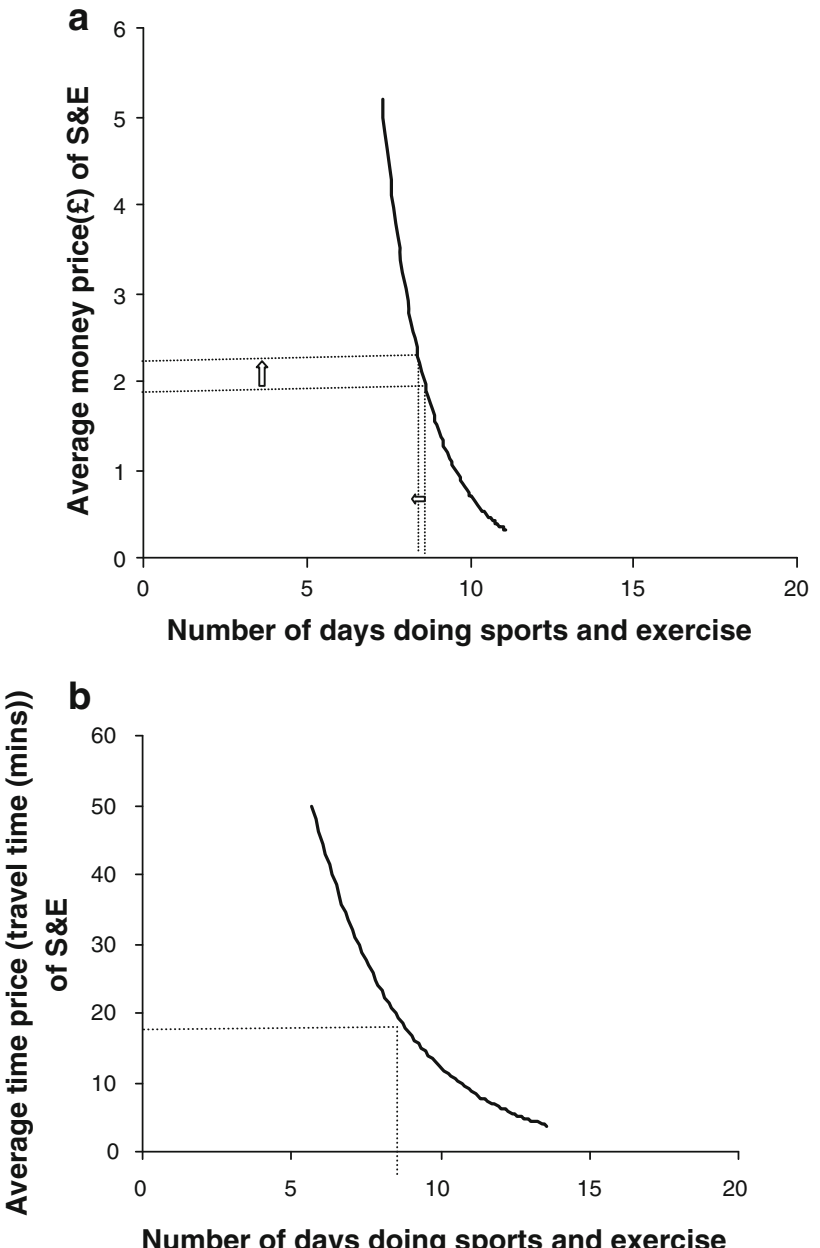

Fig. 1 Demand curves for no. of days doing sports and exercise (S\&E). a using money ('variable') price b using time price

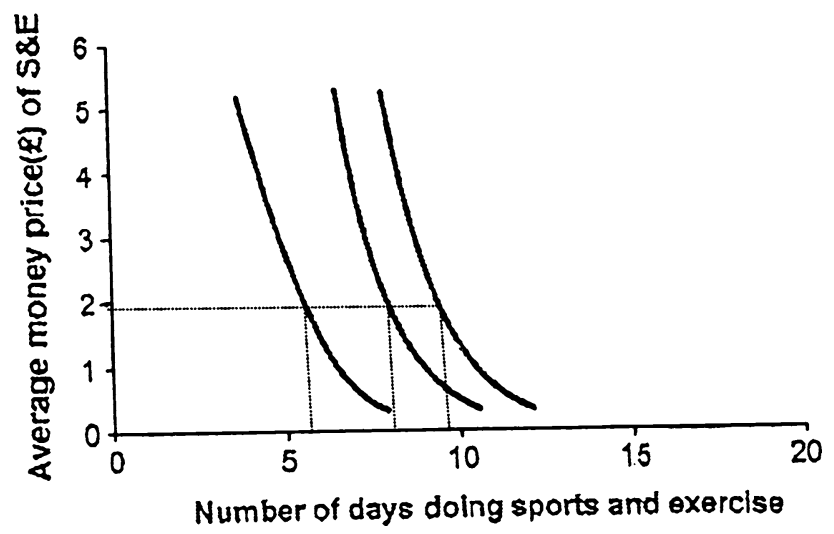

Fig. 2 Shifts in demand curve for no. of days doing sports and exercise $(\mathrm{S} \& \mathrm{E})$

\section{Model diagnostics}

The specification error tests (linktest) show that the models had good specification and that additional statistically significant regressors could only be found by chance (Table 4). The models' estimates could be considered stable as no sign of multicollinearity was found, with average variance inflation factors and tolerance levels at 1.5 and 0.7 , respectively. A reasonable proportion (between 14 and $40 \%$ ) of variation in the demand for sports and exercise was explained by the models as indicated by the adjusted and pseudo $R^{2}$.

\section{Discussion}

The findings show that people spend an average of $£ 27.41$ on sports and exercise per month and 19.8 min travelling, per occasion of participation. The money price of participation mostly included membership fees, entrance charges, and purchase of sports apparel, sports equipment and nutritional supplements. This is the only study to have shown that both high time and money prices (price per occasion) of sports and exercise may deter (although less than proportionately) participation in sports and exercise. Demand for sports and exercise was found to be price inelastic, except for meeting the recommended level of participation which was time price elastic. An explanation for this could be that meeting of recommended level requires more time and hence consumers tend to be more sensitive to extra time expenditure. Nonetheless it could also be a function of the sample as their activity levels (an average of 11 days), given intensity of participation, were close to the recommended level. Awareness of benefits promotes participation in sports and exercise and is associated with shifts in the demand curve.

Interestingly, money price appears influential only in the context of 'number of days' of participation. A plausible explanation is the offsetting responsiveness of frequency of participation and the duration per occasion of participation to changes in money price. Though money price is inversely related to the frequency of participation, it is positively related (elasticity $=0.43 ; p>0.05$ ) to the duration per occasion of participation. Nevertheless, the total effect of higher price on sports and exercise is negative because the negative correlation with frequency of participation overpowers the positive correlation with duration per occasion. For example, while a $10 \%$ higher price is associated with $2.5 \%$ fewer days, it results in a $0.3 \%$ more average time spent per occasion.

The findings on price and perceived benefits supported the predications of the economic theory underlying the empirical research. A priori expectations with respect to control variables were also met. These results were consistent across variant models, but a useful consideration is which of the models is superior? It is difficult discriminating between models given that they all showed good 
specification and fit and satisfied relevant statistical assumptions. However, if we consider the penalised loglikelihood (AIC and BIC) as a criterion, then the "total time model" appears to be the best model as it had the lowest AIC and BIC i.e. explained the most variation in sports and exercise. Nonetheless, given that all the models could be considered 'valid' it reasonable to argue that the choice of superior model should rather be based on which model is fit for purpose-what specification of demand is of interest.

Comparing the results on price to the few studies [11, $12,16]$ that had explored the effects of price on sports and exercise unsurprisingly reveals slight differences. Humphreys and Ruseski $[11,12]$ showed a positive impact of time price while Tai et al. [18] found no effect for money price. Differences in measurement of price between these studies and ours could explain why the two sets of findings vary. Time price were measured via proxies in the literature [11, 12] while money price were specified as only entrance charges [18].

A question could be raised about the completeness of the perceived benefits covered in our study. One could contend that people would expect additional benefits from physical activity participation other than these benefits. Although we could argue that the list of benefits in the questionnaire were fairly complete as they were consistent with those in the literature [19], we further explored the availability of additional benefits by asking the respondents in the illustrative survey: 'Are/is there any other benefit(s) not mentioned on the card that you think participation in sports or exercise activities could help you gain?' and the possible responses were yes or no. If yes, respondents were probed to list those benefit(s). Twenty-seven per cent $(n=16)$ of respondents answered yes and mentioned benefits, but these were found to be comparable with the list of benefits already provided in the questionnaire. There is, however, a need to verify the reliability and validity of this finding because the question was not pretested.

This study is exploratory and several caveats justify some caution in interpretation. A first set of limitations reflect on the impact of using cross-sectional data. While we have emulated usual practice in the estimations of price elasticity with cross-section data [31, 32], time-series data would be more useful. Using cross-sectional data tends to lead to higher price elasticities because a cross-section model assumes consumers have already responded to changes in prices and are at their long term equilibrium [33]. Long-run elasticities are higher than the short-run elasticities because the long run offers more time for consumers to adjust to price changes. Related to this, it is also possible that temporal trends in control variables (e.g. income, age) that might impact on price elasticity of demand are under represented in cross-sectional data. We are also aware some of the variation in prices may be due to differences between consumer rather than supply conditions. This may be caused, for example, by differences in opportunity cost of time and marginal price/benefits of information search for prices [34]. If unaccounted for, as in this study, such price variations could lead to bias and misleading elasticities [35]. Future work could consider the use of a hedonic price equation to adjust for such price variations, by regressing global price for sports and exercise on a set of factors including purchase characteristics to predict an 'adjusted price'.

A second set of limitations relates to the measurement of variables. First, the indicators of physical activity participation were measured via self-reported questionnaire. The use of self-reports to measure physical activity can be fraught with overestimation or problems with recall [25]. Alternative approaches such as use of objective measurements like accelerometers were not feasible within the constraints of this study. It is also important to note that a more complete approach to the analysis would have been to adjust for other types of physical activity (e.g. occupational activity) as participation levels in those activities may impact on sports and exercise behaviour [16]. Data limitations, however, did not allow such an investigation and future research should address this. Second, the specification of some of control variables may have influenced the robustness of estimates. For example, the low influence of income might have occurred because income had to be operationalised as a binary to ensure enough observations in categories.

A third set of limitations concerns the nature of the sample. The small sample size meant we could not account for selection bias. It is also logical to expect that the university sample may, for example, have higher levels of physical activity compared with the general population due to unobservable factors such as easier access to sporting facilities [27] — a confounding effect that may be more profound in our study given Brunel University's sporting excellence.

Although of questionable generalisability, the findings do indicate the potential for generating policy relevant information on demand-side incentives. For example, mass media campaigns could promote awareness about nonhealth benefits of participation in sports and exercise. The price elasticity of demand suggests any price changes would need to be large to encourage participation in sports and exercise. Assuming our data were generalisable and the estimates robust, we could demonstrate the potential impact of alternative policies. For example, consider two money price reduction policies (e.g. vouchers) aimed at encouraging the current number of days on which sports and exercise are undertaken: policy ' $\mathrm{A}$ ' aims at a $25 \%$ reduction and policy ' $\mathrm{B}$ ' a $100 \%$ reduction in price. 
Predictions based on the 'number of days' model indicate that the $25 \%$ lower price could result in people doing an additional half a day of sports and exercise and the latter two and half additional days. Only the $100 \%$ price reduction, people could meet the recommended level of participation (13 days), given intensity.

This was an exploratory study with limited resources, and therefore, we recommend that future studies should determine the robustness of the findings using a large nationally representative sample from England. Future analysis ought to add an extra indicator of sports and exercise-participate or not. Although that indicator is unlikely to be influenced by price of participation, it enables potential selection bias to be accounted for. Another potential consideration is to supplement selfreport data on sports and exercise with objective data in order to minimise recall bias.

This paper provides a first estimate of how demand for sports and exercise in England is correlated with time and money price and perceived benefits of participation. However, it would be important to get better evidence in order to understand these relationships and provide varied policy options to encourage participation in sports and exercise.

Acknowledgments The Health Economics Research Group at Brunel University receives funding from the Department of Health policy research programme. The views expressed in the publication are those of the authors and not necessarily those of the Department of Health. We thank all respondents who participated in the study. A draft version of this paper was discussed in the Health Economics Study Group (HESG) in January 2010, and we would like to thank participants, in particular David McDaid, for their valuable comments.

Conflict of interest The authors state that they have no conflict of interest.

Open Access This article is distributed under the terms of the Creative Commons Attribution Noncommercial License which permits any noncommercial use, distribution, and reproduction in any medium, provided the original author(s) and source are credited.

\section{References}

1. Department for Culture, Media and Sport: Before, during and after: making the most of the London 2012 Games (2008)

2. NICE: Workplace health promotion: how to encourage employees to be physically active (2008)

3. Department of Health: Be active, be healthy: a plan for getting the nation moving (2009)

4. Department of Health: Choosing activity: a physical activity action plan (2005)

5. World Health Organisation: World health report (2002)

6. World Health Organisation: Recommended amount of physical activity (2009). Accessed 3 Feb 2009

7. National Health Service: Physical activity surveillance in England: what is measured and where are the gaps? (2009)
8. Department of Health: At least five a week: evidence on the impact of physical activity and its relationship to health. A report from the Chief Medical Officer (2004)

9. Craig, R., Mindell, J.: Health survey for England 2006 (2008)

10. Pratt, M., Macera, C.A., Sallis, J.F., O’Donnel, M., Frank, L.D.: Economic interventions to promote physical activity: application of the SLOTH model. Am. J. Prev. Med. 27(3S), 136-145 (2004)

11. Humphreys, B.R., Ruseski, J.E.: Economic determinants of participation in physical activity and sport (06-13) (2006)

12. Humphreys, B.R., Ruseski, J.E.: Participation in physical activity and government spending on parks and recreation. Contemp. Econ. Policy 25(4), 538-552 (2007)

13. Sturm, R.: The economics of physical activity: societal trends and rationales for intervention. Am. J. Prev. Med. 27(3S), 126-135 (2004)

14. Cawley, J.: An economic framework for understanding physical activity and eating behaviours. Am. J. Prev. Med. 27(3S), 117-125 (2004)

15. Wanless, D.: Securing good health for the whole population (2004)

16. Wu, B., Porell, F.: Job characteristics and leisure physical activity. J. Aging Health 12(4), 538-559 (2000)

17. Gratton, C., Taylor, P.: Economics of sport and recreation, 2nd edn. E \& FN Spon, London (2000)

18. Tai, S.S., Gould, M., Smith, P., Iliffe, S.: Promoting physical activity in general practice: should prescribed exercise be free? J. R. Soc. Med. 92(2), 65-67 (1999)

19. Anokye, N.K.: An exploration of demand for physical activity. Brunel University, London (2010)

20. Adler, E.S., Clark, R.: How it's done: an invitation to social research, 3rd edn. Thomas Learning Inc, Belmont (2008)

21. Finkelstein, E.A., Brown, D.S., Brown, D.R., Buchner, D.M.: A randomized study of financial incentives to increase physical activity among sedentary older adults. Prev. Med. 47(2), 182-187 (2008)

22. Maddala, G.S.: Introduction to econometrics, 3rd edn. Wiley, Chichester (2001)

23. Lera-López, F., Rapún-Gárate, M.: Sports participation versus consumer expenditure on sport: different determinants and strategies in sports management. Eur. Sport Manag. Q. 5(2), 167-186 (2005)

24. Lera-López, F., Rapún-Gárate, M.: The demand for sport: sport consumption and participation models. J. Sport Manage. 21(1), 103-122 (2007)

25. Gillison, F.B., Standage, M., Skevington, S.M.: Relationships among adolescents' weight perceptions, exercise goals, exercise motivation, quality of life and leisure-time exercise behaviour: a self-determination theory approach. Health Educ. Res. 21(6), 836-847 (2006)

26. Downward, P.: Exploring the economic choice to participate in sport: results from the 2002 General Household Survey. Int. Rev. Appl. Econ. 21(5), 633-653 (2007)

27. Farrell, L., Shields, M.A.: Investigating the economic and demographic determinants of sporting participation in England. J. Roy. Stat. Soc. A (Stat. Soc.) 165(2), 335-348 (2002)

28. Mulvihill, C., Rivers, K., Aggleton, P.: Views of young people towards physical activity: determinants and barriers to involvement. Health Educ. 100(5), 190-199 (2000)

29. Williams, D.W., Anderson, E.S., Winett, R.A.: A review of the outcome expectancy construct in physical activity research. Ann. Behav. Med. 29, 70-79 (2005)

30. Taks, M., Renson, R., Vanreusel, B.: Of sport, time and money: an economic approach to sport participation. Int. Rev. Sociol. Sport 29(4), 381-395 (1994)

31. Deaton, A.: Estimations of own-and cross-price elasticities from household survey data. J. Econom. 36, 7-30 (1987) 
32. Deaton, A.: Price elasticities from survey data: extensions and Indonesian results. J. Econom. 44, 281-309 (1990)

33. Cadman, J., Dineen, C.: Price and income elasticity of demand for broadband subscriptions: a cross-sectional of OECD countries (2008)
34. Goldman, F., Grossman, M.: The demand for pediatric care: a hedonic approach. J. Political Econ. 86(2), 259-280 (1978)

35. Cox, T., Wohlgenant, M.: Price and quality effects in cross-sectional demand analysis. Am. J. Prev. Med. 68(4), 908-919 (1986) 